\title{
Hemodiafiltration Improves Plasma 25-Hepcidin Levels: A Prospective, Randomized, Blinded, Cross-Over Study Comparing Hemodialysis and Hemodiafiltration
}

\author{
Bergur V. Stefánsson Mats Abramson Ulf Nilsson Börje Haraldsson
}

Departments of Molecular and Clinical Medicine and Nephrology, Institute of Medicine, The Sahlgrenska Academy at University of Gothenburg, Gothenburg, Sweden

\section{Key Words}

Anticoagulation • Erythropoiesis $\cdot \beta_{2}$-Microglobulin • Hemodiafiltration • Hemodialysis • Hepcidin • Inflammation • Quality of life

\begin{abstract}
Background/Aims: Data from studies comparing the effect of hemodiafiltration (HDF) and conventional hemodialysis (HD) on clinically important outcomes are insufficient to support superiority of HDF. None of these studies has been participant-blinded. Methods: We performed a prospective, randomized, and patient-blinded cross-over study. Twenty patients on chronic HD received either HD for 2 months followed by post-dilution HDF for 2 months or in opposite order. A range of clinical parameters, as well as markers of inflammation, oxidative stress and iron metabolism was measured. Results: The two treatments were similar with respect to dialysisrelated complications, quality of life, and the biomarkers of oxidative stress and inflammation. Compared to HD, 25-hepcidin and $\beta_{2}$-microglobulin were 38 and $32 \%$, respectively, lower after 60 days of HDF ( $p<0.001$ and $p<0.01$, respectively). The consumption of ESA (erythropoietinstimulating agent) and LMWH (low-molecular-weight heparin) was significantly higher with HDF. Conclusion: In short term, HDF is not superior to HD regarding dialysis-related complications. The higher ESA consumption observed with HDF can be explained by blood clotting in tubing and dialyzers, as more anticoagulation was needed with post-dilution HDF. In a longer perspective, lowering serum hepcidin levels may improve pathological iron homeostasis.
\end{abstract}

Copyright $\odot 2012$ S. Karger AG, Basel 


\section{Introduction}

Healthy human kidneys efficiently filter waste products over a wide range of molecular masses (up to $40-60 \mathrm{kDa}$ ). On the other hand, with conventional hemodialysis (HD) treatment, only low-molecular-weight substances $(<500 \mathrm{Da})$ are effectively cleared while middlemolecular-weight substances $(>500 \mathrm{Da})$ are ineffectively removed. Consequently, these substances, many of which are putative uremic toxins [1], can accumulate and further add to the uremic burden. As a result, these patients are chronically loaded with diverse uremic toxins, which somehow lead to the various complications of uremia, including severe cardiovascular disease [1-3]. To increase the clearance of medium-sized molecules, a high permeability membrane has been developed, permitting increased hemofiltration and thereby enhanced solute clearance by convection [4]. In 1975, hemodiafiltration (HDF) was introduced. This method combined the convective clearance of hemofiltration and the diffusive clearance of $\mathrm{HD}$, resulting in improved clearance of middle-molecular-weight substances [5]. The limitation of this technique was the huge volumes of replacement solution required, a problem that was overcome by the development of HD machines that performed HDF with on-line production of replacement fluid [6]. This dialysis modality was found to be clinically safe, and optimism was evoked that HDF would provide more efficient treatment that could reduce the high morbidity in the uremic population. However, according to a Cochrane meta-analysis, evidence showing that HDF is superior to conventional HD is lacking [7]. In the same report, it is noted that no randomized study comparing HD and HDF has blinded the participants or investigators to the intervention.

The aim of this study was to perform a patient-blinded and partially investigator-blinded comparison between HD and HDF regarding a wide variety of clinical parameters, such as dialysis-related symptoms, dialysis complications and quality of life as well as consumption of LMWH (low-molecular-weight heparin) and ESA (erythropoietin-stimulating agent). In addition, we wanted to evaluate possible differences in various clinical laboratory parameters, in levels of serum markers of oxidative stress and inflammation as well as in clearance of selected middle-molecular-weight substances.

\section{Subjects and Methods}

\section{Patients}

Patients on regular HD treatment at the Hemodialysis Unit Mölndal, Sahlgrenska University Hospital, in Gothenburg, Sweden, were screened for inclusion in the study. The inclusion criteria were age $>18$ years and at least 3 months on HD treatment with either HD or HDF. Additionally, all patients had to be in clinically stable condition, without any signs of acute inflammation, infection or cardiovascular disease. Twenty patients were included, and 5 additional patients were recruited to replace dropouts that discontinued the study for various reasons. Two patients were withdrawn during the HD period, 1 because of severe pain caused by peripheral ischemia and 1 patient died. During the HDF period, 1 patient got an intracerebral bleeding without previous severe hypertension, and 1 patient requested exclusion due to severe hypertension which developed at onset of HDF. Finally, 1 patient was removed because of severe dialysis access problems.

The mean \pm SD age of the participants was $60.6 \pm 13.6$ years and the gender distribution was set to $70 \%$ males (male/female 14/6) since this reflects the distribution in the Swedish HD population [8]. The causes of renal failure were diabetic nephropathy (7 patients), chronic glomerulonephritis (4 patients), nephrosclerosis (4 patients), adult polycystic kidney disease ( 2 patients), and chronic interstitial nephritis (3 patients). The dialysis modality be- 
fore inclusion was HD in 15 patients and HDF in 5 patients. Twelve patients had central venous dialysis catheter and 8 had AV fistula, and the dry weight at inclusion was $78.9 \pm$ $15.1 \mathrm{~kg}$.

\section{Study Design}

This study is a single-center, prospective, and randomized crossover comparison of postdilution HDF and low-flux HD. The local ethics committee approved the study protocol, and informed consent was obtained from all subjects.

After inclusion, 20 patients were randomized to receive either HD or HDF for 60 days. Thereafter, they were switched to the other dialysis modality for the same period of time. The study was patient-blinded and partially investigator-blinded; the interviewers did not know which treatment was performed (see below). Study visits, with interviews and blood sample collection, were performed at baseline and on day 60 of the respective dialysis modality.

\section{Blood Pressure Measurements}

Blood pressure measurements were standardized. Only one type of automatic blood pressure equipment was used (Gambro BP 100). The pressure was measured in the same arm before and after each dialysis treatment, both supine after 10 min rest and in upright position, without delay. The average blood pressure at the three last dialysis sessions in each treatment period was used to compare blood pressure levels between the dialysis modalities. Blood pressure medications were altered as needed during the study and all changes were recorded.

\section{Questionnaires Concerning Dialysis-Related Symptoms and Quality of Life}

All interviews were double-blinded. This could be achieved because our dialysis clinic is split into two spatially distinct units with different dialysis staff, and all interviews were performed by nurses from the other team. At the interviews, patients answered health-related questions in two separate questionnaires. The first one was the Swedish version of the standardized quality of life questionnaire, IQOLA SF-36 [9]. The second one was generated by the study designers and specifically concerned 12 symptoms and health-related conditions occurring during the previous 4 weeks. The patients were asked to specify if symptoms appeared before, during or after the dialysis treatment. If appropriate, they were asked if the symptom or condition occurred after dialysis, during the night or during the following day. The results were registered on a visual analogue scale from 1 to 10 .

\section{Blood Sampling and Analyses}

All blood samples were collected from the arterial line. Analysis on pre-dialysis, routine tests, were performed without delay, while post-dialysis serum samples were centrifuged and stored at $-80^{\circ} \mathrm{C}$. The dialysis adequacy was evaluated by calculation of $\mathrm{spKt} / \mathrm{V}$ according to Daugirdas [10], and samples for measurements of post-dialysis urea were drawn 2 min after the dialysis treatment. All routine serum analyses, as well as high sensitivity CRP, were performed at our local hospital laboratory. LDL oxidation was estimated by measuring the baseline level of diene conjugation in lipid-extracted plasma LDL [11]. The plasma total antioxidant capacity was assessed by a slightly modified TEAC method (TROLOX Equivalent Antioxidant Capacity) [12]. Oxidation of proteins was determined by measuring protein carbonyl content with a spectrophotometric carbonyl assay [13]. The serum concentration of IL6 and myeloperoxidase were analyzed using commercially available ELISA kits from Diaclone, Fleming, France and Assay Designs, Inc., Ann Arbor, Mich., USA, respectively. Serum 25-hepcidin was measured at Hepcidinanalysis.com, Nijmegen, the Netherlands by a com- 
bination of weak cation exchange chromatography and time-of-flight mass spectrometry [14]. Because of insufficient amount of frozen serum, it was not possible to analyze s-hepcidin in 5 patients.

\section{Dialysis Treatment}

All treatments were carried out on AK 200 ULTRA dialysis machines (Gambro, Lund, Sweden) and with BL 200B blood tubing. Polyamide dialysis membranes were used in all treatments; low-flux (Polyflux $17 \mathrm{~L}$, effective area of $1.7 \mathrm{~m}^{2}$ ) in HD and high-flux (Polyflux 21S, effective area of $2.1 \mathrm{~m}^{2}$ ) in HDF. All treatments were patient-blinded; the dialysis machine was concealed behind a screen, making it impossible for the patient to identify which treatment was given.

In HDF, on-line post-dilution was used, and the replacement volume was standardized to $25-30 \%$ of the total blood volume treated. Anticoagulation was performed with tinzaparin sodium (Innohep ${ }^{\circledR}$, Leo Pharma, Bellerup, Denmark). For each patient, the dialysis prescription was kept constant throughout the study (total dialysis time, dialysate flow = $500 \mathrm{ml} / \mathrm{min}$, dialysate temperature and dialysate composition) and the blood flow was kept as stable as possible. In patients with an AV fistula, recirculation was measured after 4 weeks of treatment with either HD or HDF. All intradialysis symptoms and signs were registered.

\section{Data Collection and Statistical Analysis}

Microsoft Excel was used to register data and generate graphs. Data are expressed as mean $\pm \mathrm{SD}$ if not otherwise indicated. To exclude carry-over effect, all data other than frequency of intradialysis complications and total anticoagulation dose were only collected from the second month of respective treatment. Paired Student's t test or, if appropriate, nonparametric test (Wilcoxon) was used to compare means in respective treatments. Pearson correlation was used to calculate strength of association between two variables. $\chi^{2}$ test was used to compare frequency of pooled symptoms between treatments and sign test was used to compare the frequency of a specific symptom. Differences were considered significant at $\mathrm{p}<0.05$.

\section{Results}

Dialysis Efficacy and Average Dialysis Dose

The total number of dialysis sessions was 1,040, 520 with each treatment. The dialysis efficacy and average dialysis dose delivered during the study were equal between treatments. The dialysis data (mean \pm SD per dialysis session, HD/HDF) were as follows: treatment time $265 \pm 27 / 267 \pm 28 \mathrm{~min}, \mathrm{Qb} 312 \pm 32 / 310 \pm 34 \mathrm{ml} / \mathrm{min}, \mathrm{Kt} / \mathrm{V} 1.47 \pm 0.24 / 1.51 \pm 0.20$, dialyzed blood volume $82.4 \pm 5.8 / 81.2 \pm 7.1$ liter, pre-dialysis weight $80.9 \pm 14.1 / 80.6 \pm$ $14.4 \mathrm{~kg}$, post-dialysis weight $78.5 \pm 13.9 / 78.3 \pm 14.0 \mathrm{~kg}$, ultrafiltration volume $2.4 \pm 1.0 / 2.3$ \pm 1.0 liter and the replacement volume with HDF was $22.1 \pm 4.2$ liter.

\section{Incidence of Intradialysis Symptoms}

The total number of symptoms registered during treatment with HD and HDF was 204 and 200, respectively. All symptoms were mild, and the most common (HD/HDF) were muscle cramps (79/60), headache (40/45), hypotension (28/32), restless legs (10/19), and numbness in hands and feet (10/18). None of these differences were statistically significant. 
Table 1. Quality of life on day 60 of respective dialysis modality $($ mean $\pm \mathrm{SD})$

\begin{tabular}{lll}
\hline & HD & HDF \\
\hline Physical functioning & $53 \pm 26$ & $50 \pm 24$ \\
Role physical & $30 \pm 36$ & $26 \pm 39$ \\
Bodily pain & $64 \pm 28$ & $68 \pm 22$ \\
General health & $41 \pm 21$ & $41 \pm 18$ \\
Vitality & $51 \pm 26$ & $52 \pm 27$ \\
Social functioning & $75 \pm 24$ & $64 \pm 27^{*}$ \\
Role emotional & $60 \pm 41$ & $60 \pm 45$ \\
Mental health & $75 \pm 22$ & $75 \pm 18$ \\
Physical component summary & $47 \pm 14$ & $46 \pm 17$ \\
Mental component summary & $65 \pm 11$ & $63 \pm 10$ \\
\hline \multicolumn{2}{c}{${ }^{*} \mathrm{p}<0.05$ compared to HD. } \\
\hline
\end{tabular}

\section{Health Questionnaire}

All patients answered visual analogue scale questions regarding headache, nausea, dizziness, thirst, itching, muscle cramps, fatigue, restless legs, dyspnea, sleep disturbance and appetite. In summary, no differences between the two treatments were found.

\section{Quality of Life}

The results of the IQOLA SF-36 questionnaire at day 60 with respective treatment are shown in table 1 . With the exception of a lower score for social functioning with HDF ( $<<$ 0.05), there was no significant difference in quality of life between HD and HDF.

\section{Arterial Blood Pressure and Body Weight}

The arterial blood pressure was slightly higher during the last week of treatment with HDF compared to the same period on HD treatment (table 2). This was noted in all blood pressure measurements, but was only statistically significant in blood pressure measured in upright position before dialysis $(\mathrm{p}<0.05)$. The blood pressure medication was identical during the last week with respective treatment and the dry weight did not change during the study. The mean dry weight during the last week in HD and HDF was 77.1 \pm 15.1 and 76.8 $\pm 15.4 \mathrm{~kg}$, respectively.

\section{Pre-Dialysis Clinical Chemistry Parameters}

The results of pre-dialysis clinical chemistry analysis at baseline, as well as on day 60 with respective treatment, are shown in table 3. Compared to baseline, leukocyte count, screatinine and BUN were significantly lower with HD and HDF. Compared to HD, there was a trend towards lower levels of both creatinine and BUN with HDF and serum albumin was significantly lower with HDF. Additionally, $\beta 2$-microglobulin was significantly lower in HDF, both compared to baseline and compared to HD. Finally, compared to HD, treatment with HDF was associated with a trend towards lower ferritin values and higher MCV values on day 60 ( $\mathrm{p}=0.08$ in both cases). No other significant differences between the dialysis modalities were found.

\section{Post-Dialysis Markers of Inflammation, Oxidative Stress and Iron Metabolism}

The post-dialysis levels of different serum markers of inflammation and oxidative stress were measured after the last dialysis session in the respective study period (table 4). In short, no differences between levels of inflammation or oxidative stress were found. On the other 
Table 2. Systolic and diastolic blood pressure during the last three dialysis sessions of respective dialysis modality (mean $\pm \mathrm{SD})$

\begin{tabular}{|c|c|c|c|c|}
\hline & \multicolumn{2}{|l|}{ Pre-dialysis } & \multicolumn{2}{|l|}{ Post-dialysis } \\
\hline & $\mathrm{HD}$ & HDF & HD & HDF \\
\hline \multicolumn{5}{|c|}{ Systolic blood pressure, $\mathrm{mm} \mathrm{Hg}$} \\
\hline Supine & $157.5 \pm 26.1$ & $161.2 \pm 29.9$ & $157.1 \pm 22.8$ & $161.6 \pm 25.1$ \\
\hline Standing & $151.1 \pm 26.1$ & $156.4 \pm 31.1$ & $137.9 \pm 18.4$ & $143.0 \pm 24.3$ \\
\hline \multicolumn{5}{|c|}{ Diastolic blood pressure, $\mathrm{mm} \mathrm{Hg}$} \\
\hline Supine & $86.4 \pm 10.8$ & $88.9 \pm 12.6$ & $85.3 \pm 10.3$ & $86.8 \pm 12.8$ \\
\hline Standing & $86.8 \pm 12.6$ & $90.1 \pm 14.0^{*}$ & $81.8 \pm 9.5$ & $85.1 \pm 13.4$ \\
\hline
\end{tabular}

Table 3. Hematological and chemical parameters at baseline and on day 60 in the respective study period $($ mean $\pm \mathrm{SD})$

\begin{tabular}{|c|c|c|c|}
\hline & \multirow{2}{*}{$\frac{\text { Day } 0}{\text { Baseline }}$} & \multicolumn{2}{|l|}{ Day 60} \\
\hline & & HD & HDF \\
\hline Hemoglobin, g/l & $116.1 \pm 12.2$ & $116.1 \pm 8.4$ & $115.1 \pm 6.0$ \\
\hline Mean corpuscular volume $\left(\times 10^{-15} /\right.$ liter $)$ & $97.1 \pm 5.5$ & $97.2 \pm 5.7$ & $98.0 \pm 4.9$ \\
\hline Leukocyte count $\left(\times 10^{9} /\right.$ liter $)$ & $8.1 \pm 2.5$ & $7.0 \pm 1.8^{\mathrm{a}, * *}$ & $7.1 \pm 2.3^{\mathrm{a}, * *}$ \\
\hline Thrombocyte count $\left(\times 10^{9} /\right.$ liter $)$ & $241 \pm 76$ & $234 \pm 69$ & $236.5 \pm 83.1$ \\
\hline $\mathrm{s}$-sodium, mmol/l & $137.2 \pm 3.2$ & $137.3 \pm 2.3$ & $137.5 \pm 2.4$ \\
\hline $\mathrm{s}$-potassium, $\mathrm{mmol} / \mathrm{l}$ & $5.0 \pm 0.9$ & $4.9 \pm 0.6$ & $5.0 \pm 0.8$ \\
\hline s-calcium, mmol/l & $2.4 \pm 0.2$ & $2.4 \pm 0.2$ & $2.4 \pm 0.4$ \\
\hline s-phosphate, mmol/l & $2.0 \pm 0.5$ & $1.8 \pm 0.4$ & $1.7 \pm 0.4$ \\
\hline $\mathrm{s}$-bicarbonate, $\mathrm{mmol} / \mathrm{l}$ & $23.5 \pm 2.0$ & $24.2 \pm 1.6$ & $24.1 \pm 2.3$ \\
\hline $\mathrm{s}$-creatinine, $\mu \mathrm{mol} / \mathrm{l}$ & $748 \pm 240$ & $688 \pm 213^{\mathrm{a}, * *}$ & $671 \pm 192^{\mathrm{a}, * *}$ \\
\hline $\mathrm{s}-\mathrm{BUN}$ before dialysis, $\mathrm{mmol} / \mathrm{l}$ & $21.9 \pm 5.8$ & $18.1 \pm 4.5^{\mathrm{a}, * *}$ & $17.3 \pm 3.8^{\mathrm{a}, * * *}$ \\
\hline s-albumin, $g / 1$ & $34.8 \pm 3.2$ & $36.0 \pm 2.9$ & $34.3 \pm 2.6^{\mathrm{b}, * *}$ \\
\hline $\mathrm{s}$-ferritin, $\mu \mathrm{g} / \mathrm{l}$ & $302 \pm 141$ & $311 \pm 126$ & $253 \pm 95$ \\
\hline $\mathrm{s}$-hsCRP, mg/l & $11.2 \pm 12.2$ & $9.8 \pm 10.2$ & $9.6 \pm 11.1$ \\
\hline $\mathrm{s}-\beta 2$-microglobulin, mg/l & $30.6 \pm 11.9$ & $34.6 \pm 17.0$ & $23.7 \pm 8.1^{\mathrm{a}, \mathrm{b}, * * * * * *}$ \\
\hline
\end{tabular}

a Compared to baseline. ${ }^{\mathrm{b}}$ Compared to HD. ${ }^{*} \mathrm{p}<0.05 .{ }^{* *} \mathrm{p}<0.01 .{ }^{* * *} \mathrm{p}<0.001$.

Table 4. Post-dialysis markers of inflammation, oxidative stress and iron homeostasis on day 60 with respective treatment (mean $\pm \mathrm{SD})$

\begin{tabular}{lcc}
\hline & HD & HDF \\
\hline s-interleukin 6, pg/ml & $17.4 \pm 17.0$ & $18.1 \pm 11.5$ \\
s-MPO, ng/ml & $90.1 \pm 76.8$ & $93.4 \pm 59.9$ \\
s-protein carbonyl, nmol/l & $23.5 \pm 4.4$ & $23.1 \pm 4.3$ \\
s-BD-LDL, $\mu$ mol/l & $44.4 \pm 13.8$ & $41.1 \pm 13.3$ \\
s-TEAC, $\mu \mathrm{mol} / \mathrm{l}$ Trolox & $4.0 \pm 0.6$ & $4.1 \pm 0.7$ \\
s-hepcidin, nmol/l & $11.1 \pm 5.4$ & $6.9 \pm 2.9^{* *}$ \\
\hline
\end{tabular}

${ }^{* *} \mathrm{p}<0.01$ versus HD. 


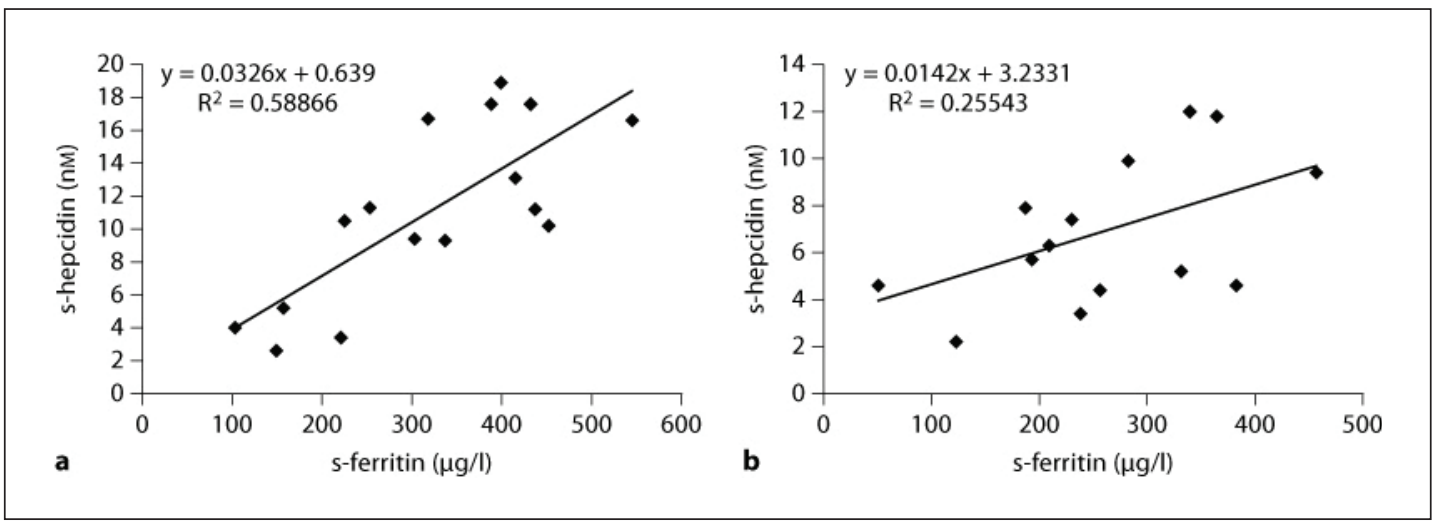

Fig. 1. Post-dialysis serum hepcidin values plotted against corresponding pre-dialysis serum ferritin levels. a HD, $\mathrm{p}=0.001$. $\mathbf{b} \mathrm{HDF}, \mathrm{p}=0.17$.

hand, the level of post-dialysis hepcidin was 38\% lower after treatment with HDF and it was correlated to corresponding pre-dialysis ferritin as seen in figure 1 ( $\mathrm{p}=0.001$ after HD and $\mathrm{p}=0.17$ after $\mathrm{HDF})$.

\section{ESA, i.v. Iron and Anticoagulation Consumption}

We calculated the individual ESA and iron consumption during the second month of respective treatment. Two patients did not need any ESA and the variation among the other 18 patients was large. ESA consumption was significantly higher with HDF. The median ESA dose in patients that needed ESA $(\mathrm{n}=18)$ was $136 \mathrm{IU} / \mathrm{kg} /$ week for HD and $163 \mathrm{IU} / \mathrm{kg} /$ week for $\mathrm{HDF}(\mathrm{p}<0.05)$. Iron consumption was also higher during treatment with HDF, albeit not significant. The median i.v. iron dose during HD was $350 \mathrm{mg} / \mathrm{month}$ and $400 \mathrm{mg} / \mathrm{month}$ during HDF (n.s.). The total LMWH dose was 33.6\% higher during treatment with HDF; the mean dose with $\mathrm{HD}$ was $4,876 \pm 1,518$ IU per dialysis session, compared to $6,514 \pm 1,668$ IU per session with HDF ( $\mathrm{p}=0.001)$. Further, 4 out of $520 \mathrm{HDF}$ treatments were terminated ahead of schedule because of coagulation in the tubing and/or dialyzer.

\section{Discussion}

In this short-term, prospective, blinded, randomized trial, we compared low-flux HD and post-dilution HDF regarding a wide variety of clinical parameters. The major differences found were due to better clearance of middle-molecular-weight substances, such as $\beta 2$-microglobulin and 25-hepcidin, by HDF.

$\beta 2$-microglobulin [15] has a molecular weight of $11,800 \mathrm{Da}$. It is normally cleared from plasma by glomerular filtration and accumulates in severe renal failure. With time, this can lead to amyloid formation and eventually amyloid depositions in soft tissues, such as joins and vessel walls [16]. Even though most of these depositions are asymptomatic with unclear clinical relevance [17], patients receiving HD over many years can develop dialysis-related amyloidosis with, for example, erosive arthritis and carpal tunnel syndrome [16].

The clearance of $\beta 2$-microglobulin is higher with HDF than with HD [18-21]. However, the impact on lowering pre-dialysis $\beta 2$-microglobulin by HDF has been moderate and often not significant $[20,22]$, which probably is due a resistance to $\beta 2$-microglobulin transfer between body compartments [22]. Nevertheless, we found significantly lower pre-dialysis se- 
Nephron Extra 2012;2:55-65

DOI: $10.1159 / 000336482$

Published online: March 28, 2012

Stefánsson et al.: Hemodiafiltration Improves Plasma 25-Hepcidin Levels

rum $\beta 2$-microglobulin levels with HDF. The clinical benefit of reducing $\beta 2$-microglobulin by HDF is unclear and even though small studies indicate reduction of clinically relevant dialysis-related amyloidosis by convective therapies [23] this has yet to be confirmed in larger long-term trials [7].

25 -Hepcidin, a 25 -amino acid peptide hormone produced by the hepatocytes, is a key regulator of iron homeostasis [24]. It binds to, and induces internalization of ferroportin, a transmembrane iron channel present in enterocytes, macrophages and hepatocytes [25]. Thereby, iron transport is hindered and increased hepcidin levels can lead to true iron deficiency by decreasing intestinal iron absorption, and to functional iron deficiency by blocking iron release from iron stores. Hepcidin production is induced by inflammation and iron overload [26, 27], two common findings in patients with chronic kidney disease. Further, hepcidin is eliminated by the kidneys and, indeed, patients on chronic HD treatment have increased serum hepcidin levels $[28,29]$. The level of serum hepcidin correlates very well with the level of serum ferritin [29-32], and our results are in line with these reports (fig. 1).

In the present study, post-dialysis serum hepcidin at day 60 was $38 \%$ lower in the HDF group compared to HD. Hepcidin is a middle-molecular-weight substance with a molecular weight of 2,791 Da [33] and is eliminated by both low- and high-flux HD [32]. The median reference level of serum hepcidin measured by mass spectroscopy is $4.2 \mathrm{nM}$ (range $0.5-13.9$ ) [34]. In our patients, serum hepcidin was within this interval in all cases after treatment with HDF (median 6.9, range 2.2-12.0), whereas $31 \%$ of the patients had serum hepcidin values outside these limits after HD (median 10.9, range 2.6-18.9).

The clinical benefit of lowering hepcidin levels by convective dialysis treatments remains to be investigated. However, patients with chronic renal failure often suffer from functional iron deficiency, which probably is caused by pathologically high hepcidin levels in the circulation [35]. In this condition, transferrin saturation is low even though iron stores are high, and potentially toxic intravenous iron administration is necessary to maintain adequate erythropoiesis. In this way, a vicious circle can arise, leading to further increase in the hepcidin level. Therefore, it seems reasonable that efforts in lowering the level of hepcidin in patients with chronic renal failure will bring the iron homeostasis towards a more normal state. Our findings, with a trend towards lower ferritin levels and increased MCV after 2 months of treatment with HDF, are in line with this hypothesis, indicating iron mobilization from the stores. This is further supported by Lin et al. [36], who reported lower ferritin levels and better iron utilization with HDF.

Some reports indicate better hemoglobin levels and lower erythropoietin need in patients treated with HDF [36-39]. However, there is not sufficient evidence to support this [7] and we did not notice any difference in the hemoglobin levels between HD and HDF. On the other hand, more iron and ESA were administrated during treatment with HDF. The significant increase in ESA dose with HDF is most likely explained by increased clotting in tubing and dialyzers secondarily to increased hemoconcentration with post-dilution HDF. Indeed, a 33\% higher LMWH dose was administrated during HDF, a dose that apparently was too low.

Our study is the first randomized participant-blinded trial comparing the frequency of intradialysis complications, dialysis-related symptoms and quality of life between HD and HDF. We found that treatment with HDF was well tolerated with the same overall frequency of intradialysis complications, which is in agreement with another randomized but not blinded study [40]. In particular, we did not find lower frequency of hypotension during $\mathrm{HDF}$, which is in contrast to several reports on convective treatments [41, 42], but in line with other studies [7, 40]. Further, regarding dialysis-related symptoms, well-being and quality of life, no difference was noted between treatments, which is in line with a 12-month randomized study [20]. We cannot explain our finding of significant lower social functioning at the end of the HDF period. 
A small elevation in arterial blood pressure has been described with convective HD treatment [42]. In line with this report, we noted a slight elevation in blood pressure during the last week on HDF compared to HD, albeit only significant in diastolic pressure measured before dialysis in upright position. The clinical relevance of this small blood pressure elevation is unclear, but it could hypothetically reflect better baroreceptor sensibility with HDF. No patient on HDF treatment needed additional prescription of anti-hypertensive drugs. However, cases with accelerated hypertension after initiation of HDF have been reported [20], and in our study 1 patient was withdrawn because of severe hypertension that occurred directly after HDF onset.

High mortality and severe atherosclerosis in patients with chronic renal failure have been related to inflammation and increased oxidative stress. We evaluated the level of different post-dialysis parameters of inflammation and oxidative stress but found no difference between the treatments, which is in line with other studies [38, 43]. However, the possible effect of HDF on oxidative stress is an unresolved issue as studies have shown increased [44], reduced $[40,45]$ or no effect [46].

Serum phosphate is more efficiently removed by HDF compared to HD [20, 40, 47]. Even though data are insufficient to conclude that HDF is superior regarding phosphate control [7], recently published data from ongoing large trial support this [48]. We found no superiority of HDF regarding phosphate control; however, the present study was not designed to specifically investigate this issue and the dose of phosphate binders was altered as needed.

We noticed a significant decrease in pre-dialysis serum albumin levels during HDF. Likely, this reflects some albumin removal by HDF, a finding that has also been observed by others $[45,49]$. The clinical relevance of this is not clear.

In summary, our data allow us to conclude that treatment with HD and HDF is similar regarding intra- and interdialysis complications. We found only small differences, mainly secondary to increased clearance of middle-molecular-weight substances. The most interesting finding was the lower level of serum hepcidin with HDF, indicating that more normal iron homeostasis with lower degree of functional iron deficiency could, in theory, be achieved by HDF. This remains to be investigated in trials of longer duration than 60 days.

\section{Acknowledgements}

This study was supported by the Swedish Medical Research Council 9898, the Inga-Britt and Arne Lundberg Research Foundation, the John and Brit Wennerström Research Foundation, the Medical Association of Gothenburg, and the Sahlgrenska University Hospital Grant LUA/ALF.

\section{References}

$>1$ Vanholder R, Glorieux G, Lameire N: Uraemic toxins and cardiovascular disease. Nephrol Dial Transplant 2003; 18:463-466.

-2 Foley RN, Parfrey PS: Cardiovascular disease and mortality in ESRD. J Nephrol 1998;11:239-245.

-3 Cheung AK, Sarnak MJ, Yan G, Dwyer JT, Heyka RJ, Rocco MV, Teehan BP, Levey AS: Atherosclerotic cardiovascular disease risks in chronic hemodialysis patients. Kidney Int 2000;58:353-362.

-4 Henderson LW, Colton CK, Ford CA: Kinetics of hemodiafiltration. II. Clinical characterization of a new blood cleansing modality. J Lab Clin Med 1975;85:372-391.

-5 Leber HW, Wizemann V, Goubeaud G, Rawer P, Schutterle G: Hemodiafiltration: a new alternative to hemofiltration and conventional hemodialysis. Artif Organs 1978;2:150-153.

6 Ledebo I: On-line hemodiafiltration: technique and therapy. Adv Ren Replace Ther 1999;6:195-208. 
Nephron Extra 2012;2:55-65

DOI: $10.1159 / 000336482$

Published online: March 28, 2012

Stefánsson et al.: Hemodiafiltration Imprc

7 Rabindranath KS, Strippoli GF, Daly C, Roderick PJ, Wallace S, MacLeod AM: Haemodiafiltration, haemofiltration and haemodialysis for end-stage kidney disease. Cochrane Database Syst Rev 2006;CD006258.

-8 Schon S, Ekberg H, Wikstrom B, Oden A, Ahlmen J: Renal replacement therapy in Sweden. Scand J Urol Nephrol 2004;38:332-339.

9 Sullivan M, Karlsson J, Ware JE: Sf-36 Health Survey, Swedish Manual and Interpretation Guide. Göteborg, Sahlgrenska University Hospital, 1994.

-10 Daugirdas JT: Second generation logarithmic estimates of single-pool variable volume Kt/V: an analysis of error. J Am Soc Nephrol 1993;4:1205-1213.

-11 Ahotupa M, Ruutu M, Mantyla E: Simple methods of quantifying oxidation products and antioxidant potential of low density lipoproteins. Clin Biochem 1996;29:139-144.

-12 Erel O: A novel automated direct measurement method for total antioxidant capacity using a new generation, more stable ABTS radical cation. Clin Biochem 2004;37:277-285.

-13 Reznick AZ, Packer L: Oxidative damage to proteins: spectrophotometric method for carbonyl assay. Methods Enzymol 1994;233:357-363.

-14 Kroot JJ, Laarakkers CM, Geurts-Moespot AJ, Grebenchtchikov N, Pickkers P, van Ede AE, Peters HP, van Dongen-Lases E, Wetzels JF, Sweep FC, Tjalsma H, Swinkels DW: Immunochemical and mass-spectrometry-based serum hepcidin assays for iron metabolism disorders. Clin Chem 2010;56: $1570-1579$.

-15 Vincent C, Revillard JP: Beta-2-microglobulin and HLA-related glycoproteins in human urine and serum. Contrib Nephrol 1981;26:66-88.

-16 Miyata T, Jadoul M, Kurokawa K, Van Ypersele de Strihou C: Beta-2 microglobulin in renal disease. J Am Soc Nephrol 1998;9:1723-1735.

17 Dember LM, Jaber BL: Dialysis-related amyloidosis: late finding or hidden epidemic? Semin Dial 2006;19:105-109.

-18 Kerr PB, Argiles A, Flavier JL, Canaud B, Mion CM: Comparison of hemodialysis and hemodiafiltration: a long-term longitudinal study. Kidney Int 1992;41:1035-1040.

19 Lornoy W, Becaus I, Billiouw JM, Sierens L, van Malderen P: Remarkable removal of beta-2-microglobulin by on-line hemodiafiltration. Am J Nephrol 1998;18:105-108.

-20 Ward RA, Schmidt B, Hullin J, Hillebrand GF, Samtleben W: A comparison of on-line hemodiafiltration and high-flux hemodialysis: a prospective clinical study. J Am Soc Nephrol 2000;11:2344-2350.

-21 Lin CL, Yang CW, Chiang CC, Chang CT, Huang CC: Long-term on-line hemodiafiltration reduces predialysis beta-2-microglobulin levels in chronic hemodialysis patients. Blood Purif 2001;19:301307.

-22 Ward RA, Greene T, Hartmann B, Samtleben W: Resistance to intercompartmental mass transfer limits beta2-microglobulin removal by post-dilution hemodiafiltration. Kidney Int 2006;69:14311437.

-23 Nakai S, Iseki K, Tabei K, Kubo K, Masakane I, Fushimi K, Kikuchi K, Shinzato T, Sanaka T, Akiba T: Outcomes of hemodiafiltration based on Japanese dialysis patient registry. Am J Kidney Dis 2001; 38:S212-S216.

24 Babitt JL, Lin HY: Molecular mechanisms of hepcidin regulation: implications for the anemia of CKD. Am J Kidney Dis 2010;55:726-741.

- 25 Nemeth E, Tuttle MS, Powelson J, Vaughn MB, Donovan A, Ward DM, Ganz T, Kaplan J: Hepcidin regulates cellular iron efflux by binding to ferroportin and inducing its internalization. Science 2004; 306:2090-2093.

- 26 Nemeth E, Rivera S, Gabayan V, Keller C, Taudorf S, Pedersen BK, Ganz T: Il-6 mediates hypoferremia of inflammation by inducing the synthesis of the iron regulatory hormone hepcidin. J Clin Invest 2004;113:1271-1276.

-27 Pigeon C, Ilyin G, Courselaud B, Leroyer P, Turlin B, Brissot P, Loreal O: A new mouse liver-specific gene, encoding a protein homologous to human antimicrobial peptide hepcidin, is overexpressed during iron overload. J Biol Chem 2001;276:7811-7819.

-28 Malyszko J, Malyszko JS, Pawlak K, Mysliwiec M: Hepcidin, iron status, and renal function in chronic renal failure, kidney transplantation, and hemodialysis. Am J Hematol 2006;81:832-837.

-29 Peters HP, Laarakkers CM, Swinkels DW, Wetzels JF: Serum hepcidin-25 levels in patients with chronic kidney disease are independent of glomerular filtration rate. Nephrol Dial Transplant 2010; 25:848-853. 
-30 Kato A, Tsuji T, Luo J, Sakao Y, Yasuda H, Hishida A: Association of prohepcidin and hepcidin-25 with erythropoietin response and ferritin in hemodialysis patients. Am J Nephrol 2008;28:115-121.

-31 Ashby DR, Gale DP, Busbridge M, Murphy KG, Duncan ND, Cairns TD, Taube DH, Bloom SR, Tam FW, Chapman RS, Maxwell PH, Choi P: Plasma hepcidin levels are elevated but responsive to erythropoietin therapy in renal disease. Kidney Int 2009;75:976-981.

-32 Weiss G, Theurl I, Eder S, Koppelstaetter C, Kurz K, Sonnweber T, Kobold U, Mayer G: Serum hepcidin concentration in chronic haemodialysis patients: associations and effects of dialysis, iron and erythropoietin therapy. Eur J Clin Invest 2009;39:883-890.

- 33 Ward DG, Roberts K, Stonelake P, Goon P, Zampronio CG, Martin A, Johnson PJ, Iqbal T, Tselepis C: SELDI-TOF-MS determination of hepcidin in clinical samples using stable isotope labelled hepcidin as an internal standard. Proteome Sci 2008;6:28.

-34 Kroot JJ, Hendriks JC, Laarakkers CM, Klaver SM, Kemna EH, Tjalsma H, Swinkels DW: (Pre)analytical imprecision, between-subject variability, and daily variations in serum and urine hepcidin: implications for clinical studies. Anal Biochem 2009;389:124-129.

- 35 Young B, Zaritsky J: Hepcidin for clinicians. Clin J Am Soc Nephrol 2009;4:1384-1387.

-36 Lin CL, Huang CC, Yu CC, Wu CH, Chang CT, Hsu HH, Hsu PY, Yang CW: Improved iron utilization and reduced erythropoietin resistance by on-line hemodiafiltration. Blood Purif 2002;20:349356.

-37 Bonforte G, Grillo P, Zerbi S, Surian M: Improvement of anemia in hemodialysis patients treated by hemodiafiltration with high-volume on-line-prepared substitution fluid. Blood Purif 2002;20:357363.

-38 Vaslaki LR, Berta K, Major L, Weber V, Weber C, Wojke R, Passlick-Deetjen J, Falkenhagen D: Online hemodiafiltration does not induce inflammatory response in end-stage renal disease patients: results from a multicenter cross-over study. Artif Organs 2005;29:406-412.

-39 Maduell F, del Pozo C, Garcia H, Sanchez L, Hdez-Jaras J, Albero MD, Calvo C, Torregrosa I, Navarro V: Change from conventional haemodiafiltration to on-line haemodiafiltration. Nephrol Dial Transplant 1999;14:1202-1207.

-40 Vaslaki L, Major L, Berta K, Karatson A, Misz M, Pethoe F, Ladanyi E, Fodor B, Stein G, Pischetsrieder M, Zima T, Wojke R, Gauly A, Passlick-Deetjen J: On-line haemodiafiltration versus haemodialysis: stable haematocrit with less erythropoietin and improvement of other relevant blood parameters. Blood Purif 2006;24:163-173.

-41 Maggiore Q, Pizzarelli F, Dattolo P, Maggiore U, Cerrai T: Cardiovascular stability during haemodialysis, haemofiltration and haemodiafiltration. Nephrol Dial Transplant 2000;15(suppl 1):68-73.

-42 Altieri P, Sorba G, Bolasco P, Ledebo I, Ganadu M, Ferrara R, Menneas A, Asproni E, Casu D, Passaghe M, Sau G, Cadinu F: Comparison between hemofiltration and hemodiafiltration in a long-term prospective cross-over study. J Nephrol 2004;17:414-422.

-43 Bossola M, Muscaritoli M, Tazza L, Giungi S, Panocchia N, Rossi Fanelli F, Luciani G: Switch from bicarbonate hemodialysis to hemodiafiltration with online regeneration of the ultrafiltrate (HFR): effects on nutritional status, microinflammation, and beta-microglobulin. Artif Organs 2005;29: 259-263.

-44 Morena M, Cristol JP, Bosc JY, Tetta C, Forret G, Leger CL, Delcourt C, Papoz L, Descomps B, Canaud B: Convective and diffusive losses of vitamin $\mathrm{C}$ during haemodiafiltration session: a contributive factor to oxidative stress in haemodialysis patients. Nephrol Dial Transplant 2002;17:422-427.

-45 Tomo T, Matsuyama K, Nasu M: Effect of hemodiafiltration against radical stress in the course of blood purification. Blood Purif 2004;22(suppl 2):72-77.

-46 Lucchi L, Banni S, Botti B, Cappelli G, Medici G, Melis MP, Tomasi A, Vannini V, Lusvarghi E: Conjugated diene fatty acids in patients with chronic renal failure: evidence of increased lipid peroxidation? Nephron 1993;65:401-409.

-47 Zehnder C, Gutzwiller JP, Renggli K: Hemodiafiltration - a new treatment option for hyperphosphatemia in hemodialysis patients. Clin Nephrol 1999;52:152-159.

-48 Penne EL, van der Weerd NC, van den Dorpel MA, Grooteman MP, Levesque R, Nube MJ, Bots ML, Blankestijn PJ, ter Wee PM: Short-term effects of online hemodiafiltration on phosphate control: a result from the randomized controlled convective transport study (contrast). Am J Kidney Dis 2010; 55:77-87.

-49 Combarnous F, Tetta C, Cellier CC, Wratten ML, Custaud, De Catheu T, Fouque D, David S, Carraro G, Laville M: Albumin loss in on-line hemodiafiltration. Int J Artif Organs 2002;25:203-209. 